\title{
Pregnancy Outcomes in various Types of Placenta Previa: A Clinical Study
}

\author{
Krupa BM*, Asha Swarup, Padma, Geetha, Vanisha Anand and Shruthi S \\ Department of OBG, Ramaiah Medical College Hospital, India
}

Submission: June 18, 2021; Published: July 01, 2021

*Corresponding author: Krupa BM, Department of OBG, Ramaiah Medical College Hospital, India

\begin{abstract}
Background: Placenta previa is one of the dreaded complications in obstetrics due to its associated adverse maternal and perinatal outcome.

Aim: To evaluate maternal and fetal outcomes in women with placenta previa.

Methods: A hospital based retrospective clinical study carried out in the Department of Obstetrics and Gynaecology of Ramaiah Medical College and Hospital, Bangalore, from August 2013 to August 2019.

Results: The incidence of placenta previa was found to be $0.48 \%$. Maximum patients were referred within the age group of 25-35 years and were multigravida. Mean gestational age at delivery was between 34-36 weeks. Mode of delivery was caesarean section in almost all cases (97.4\%). Outcome was studied by need of blood transfusion in $43.6 \%$, postpartum haemorrhage in $43.6 \%$, adherent placenta previa in $20.5 \%$, hysterectomy in $15.4 \%$, ICU admission in $15.4 \%$ and no significant effect on perinatal outcome.
\end{abstract}

Conclusion: Incidence of placenta previa is high in patients with previous cesarean section and multiparous women. There is a need for comprehensive obstetrics care to appropriately treat placenta previa and its complications.

\section{Introduction}

Placenta previa (PP) occurs when the placenta is wholly or partially implanted in the lower uterine segment. The classical features of bleeding in placenta previa is sudden onset, painless, causeless and recurrent [1]. The exact cause of PP is not known, but its association with various risk factors such as advanced maternal age, multiparity, previous miscarriages, previous caesarean section or previous uterine surgeries, and cigarette smoking is well documented [2,3]. The estimated global prevalence of PP is 5.2 per 1000 pregnant women, although there is significant international variation, whereby the prevalence is found to be highest among Asian studies [4]. Given the rising incidence of caesarean section combined with increasing maternal age, the number of cases of PP and its complications, including placenta accreta (PA), will continue to increase. The condition is associated with significant maternal morbidity like haemorrhagic shock, increased operative interventions and sepsis and perinatal morbidity and mortality like preterm delivery and its related complications like low birth weight, birth asphyxia and neonatal sepsis [5]. The indication for emergency peripartum hysterectomy in recent years has been changed from atonic uterus to abnormal placentation which has now become a common indication due to the increased number of pregnant women with previous caesarean scar [6]. We undertook the current study to evaluate the risk factors and also assess the feto maternal outcomes for various types of PP.

\section{Aims and Objectives}

\section{Aim}

To evaluate maternal and fetal outcomes in women with placenta previa.

\section{Objectives}

To assess the demographic features, risk factors, obstetric management and pregnancy outcomes in women with placenta previa.

\section{Materials and Methods}

We performed a retrospective review, covering a 6-year period from August 2013 to August 2019, of women admitted to the obstetric unit of Ramaiah Medical College Hospital, a tertiary referral teaching hospital in Bangalore, India. Data were collected 
from the case notes of women who were found to have PP on transabdominal or transvaginal ultrasound scanning and in whom the diagnosis was confirmed during Caesarean section. Calculation of gestational age was determined by the last menstrual periods and first-trimester ultrasound. The transabdominal ultrasound examinations were performed with the bladder half-full, and the distance between the lower edge of the placenta and the internal os was measured. The transvaginal ultrasound examinations were performed with the bladder empty. The diagnosis of placenta accreta5 was suspected in the presence of the following sonographic features: irregularly shaped lacunae of placenta, thinning of the myometrium overlying the placenta, protrusion of the placenta into the bladder, loss of the retro placental space.

All singleton pregnancies with placenta previa beyond 28 weeks of gestational age, confirmed by ultrasonography, irrespective of their parity, type of placenta previa were included in the study. For practical purpose of management, if placenta was more than two centimetres from the internal os, and asymptomatic, antenatal mother was allowed a trial of vaginal delivery.
Demographic characteristics of women included in the study, together with details of surgical findings and procedures, the volume of blood transfusions, and complications like development of hypovolemic shock, DIC, renal failure and maternal deaths were extracted from the medical records. The neonatal outcomes including gestational age at delivery, APGAR score, birth weight, need for NICU admission, still birth rate, neonatal mortality rate, presence of congenital anomalies was extracted from the neonatal case notes. Additional procedures required like uterine packing, balloon tamponade, B-Lynch Sutures/stepwise devascularization of uterus; internal iliac artery ligation and hysterectomy when needed to control bleeding were recorded. Both the mother and baby were followed up throughout the period of their hospitalization till discharge. Statistical analysis was performed using SPSS version 20. Qualitative data like age, parity, previous mode of delivery etc, was calculated by simple frequencies and percentages. Nonparametric one sample test such as chi square test and binomial tests were used. A pvalue of $<0.05$ was considered statistically significant.

\section{Result}

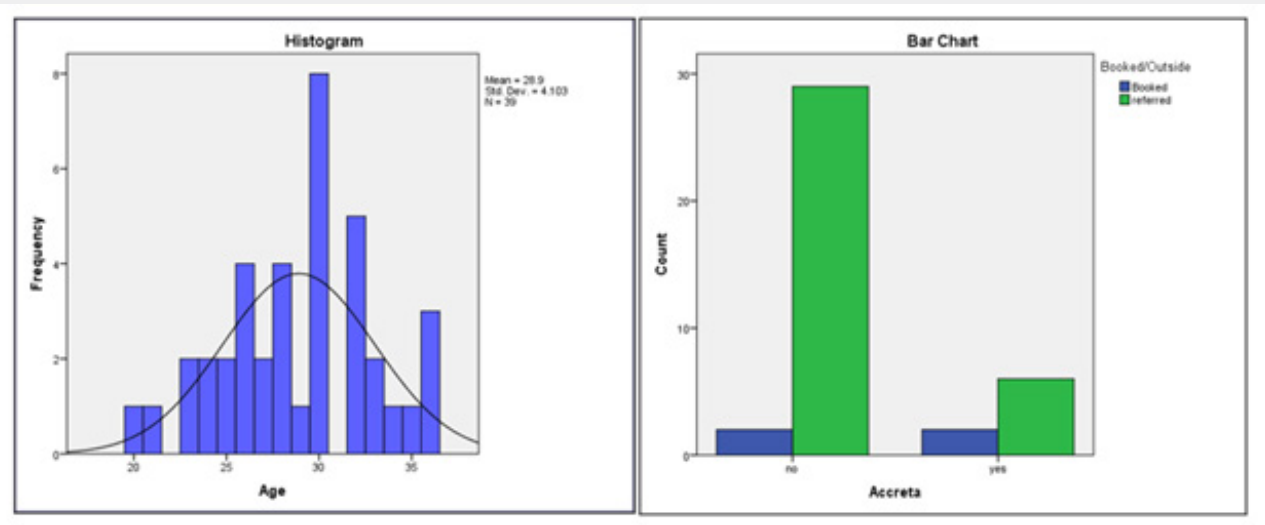

Figure 1: Non parametric one sample test such as chi square test and binomial tests were used.A pvalue of $<0.05$ was considered statistically significant.

Table 1: Demographic variables and risk factors associated with placenta previa.

\begin{tabular}{|c|c|c|c|}
\hline Variable & PP without PA [n(\%)] & PP with PA [n(\%)] & $P$ value \\
\hline \multicolumn{3}{|c|}{ Maternal Age (Years) } & \\
\hline$<25$ years & $5(12.8 \%)$ & $1(2.6 \%)$ & \multirow{3}{*}{0.641} \\
\hline 25-35 years & $23(59 \%)$ & $7(17.9 \%)$ & \\
\hline$>35$ years & $3(7.7 \%)$ & $0(0 \%)$ & \\
\hline \multicolumn{3}{|c|}{ Parity } & \\
\hline Nulliparous & $10(25.6 \%)$ & $1(2.6 \%)$ & \multirow{3}{*}{$0.00^{*}$} \\
\hline$<2$ & $16(41 \%)$ & $4(10.3 \%)$ & \\
\hline$>/=2$ & $5(12.8 \%)$ & $3(7.7 \%)$ & \\
\hline \multicolumn{3}{|c|}{ Booking Status } & \\
\hline Booked cases & $2(5.1 \%)$ & $2(5.1 \%)$ & \multirow{2}{*}{$0.00^{*}$} \\
\hline Referred cases & $29(74.4 \%)$ & $6(15.4 \%)$ & \\
\hline
\end{tabular}


Journal of Gynecology and Women's Health

\begin{tabular}{|c|c|c|c|}
\hline \multicolumn{3}{|c|}{ Previous Caesarean Section } & \\
\hline Previous 1 section & $13(33.3 \%)$ & $3(7.7 \%)$ & \multirow{2}{*}{$0.006^{*}$} \\
\hline Previous 2 or more sections & $5(12.8 \%)$ & $3(7.7 \%)$ & \\
\hline Previous miscarriage & $12(30.8 \%)$ & $4(10.3 \%)$ & $0(0 \%)$ \\
\hline Previous placenta previa & $0(0 \%)$ & - \\
\hline
\end{tabular}

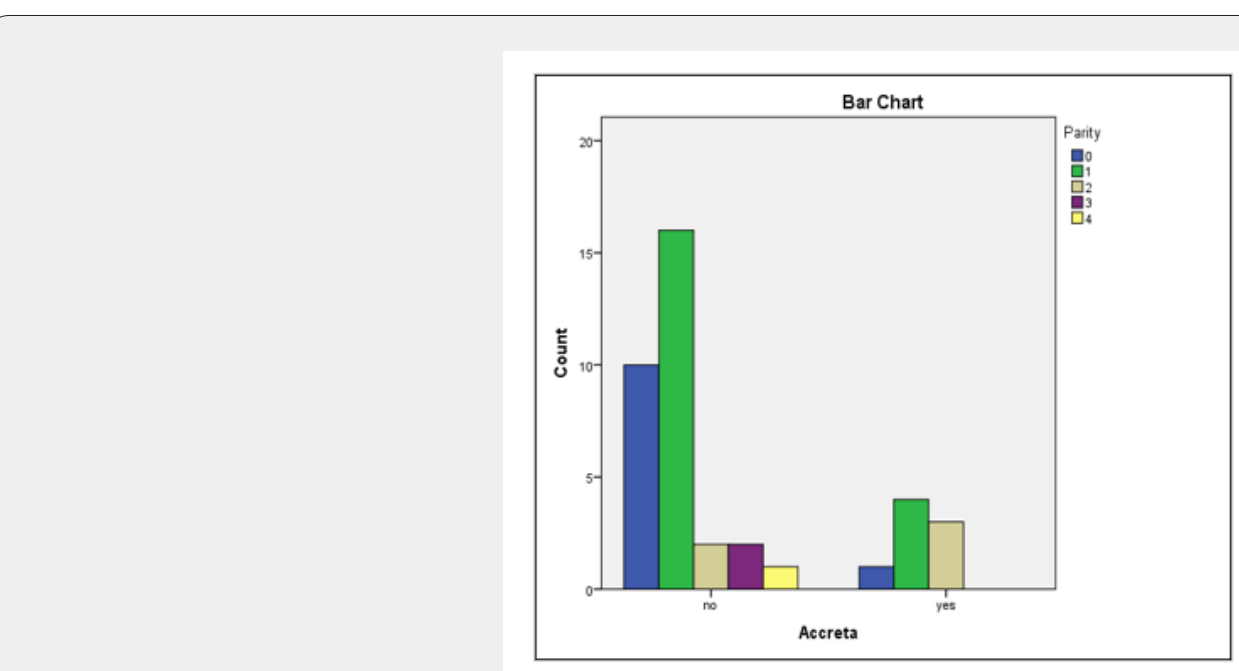

Figure 2: A total of 39 cases with placenta previa were included in our study during the study period. The mean age of the study individuals was 26.9 years with majority women falling between $25-35$ years of age group.

(Table 1) (Figures 1 \& 2) A total of 39 cases with placenta previa were included in our study during the study period. The mean age of the study individuals was 26.9 years with majority women falling between 25-35 years of age group. The incidence of PP with respect to parity was $28.2 \%$ among nulliparous and the remaining cases were primiparous or multiparous. In our study

Table 2: Types of placenta previa among the study population.

\begin{tabular}{|c|c|c|c|}
\hline & PP with PA [N(\%)] & PP without PA & $p$ value \\
\hline TYPE I & $2(5.1 \%)$ & $5(12.8 \%)$ & \multirow{5}{*}{$0.001^{*}$} \\
\hline TYPE IIa (anterior) & $0(0 \%)$ & $8(20.5 \%)$ & \\
\hline TYPE IIb (posterior) & $0(0 \%)$ & $3(7.7 \%)$ & \\
\hline TYPE III & $0(0 \%)$ & $5(12.8 \%)$ & \\
\hline TYPE IV & $6(15.4 \%)$ & $10(25.6 \%)$ & \\
\hline
\end{tabular}

Table 2 With respect to types of placenta previa based on for majority of cases with placenta accreta (75\%). 17.9\% of cases classification given by Jaunix and Campbell, $41 \%$ of the cases with had type I PP and least common was type IIb (posterior) PP PP had type IV or central/complete placenta previa and accounted accounting for $7.7 \%$ cases.

Table 3: Types of placenta previa among the study population.

\begin{tabular}{|c|c|c|}
\hline & N(\%) & \multicolumn{1}{|c|}{ P Value } \\
\hline \multicolumn{2}{|c|}{ Gestational Age at Delivery [Mean249.8 days] } \\
\hline$<34$ weeks (<238 days) & $8(20.5 \%)$ & \\
\hline $34-37$ weeks (238-259 days) & $15(38.5 \%)$ & \multirow{2}{*}{0.232} \\
\hline$>37$ weeks (>259 days) & $23(59 \%)$ & - \\
\hline
\end{tabular}




\section{Journal of Gynecology and Women's Health}

\begin{tabular}{|c|c|c|}
\hline \multicolumn{3}{|c|}{ Mode Of Delivery } \\
\hline Emergency CS & $24(61.5 \%)$ & \multirow{3}{*}{$0.00^{*}$} \\
\hline Elective CS & $14(35.9 \%)$ & \\
\hline Vaginal delivery & $1(2.6 \%)$ & \\
\hline \multicolumn{3}{|c|}{ Blood Loss [Mean 646.15 Ml] } \\
\hline$<1000 \mathrm{ml}$ & 35 (89.7\%) & \multirow{2}{*}{$0.00^{*}$} \\
\hline$>1000 \mathrm{ml}$ & $4(10.3 \%)$ & \\
\hline
\end{tabular}

Table 3 Mean gestational age at delivery was 249.8 days in our study with $59 \%$ cases having preterm delivery. $61.5 \%$ of the cases landed up with emergency caesarean section as they were referred to our hospital with complications. Only one case $(2.6 \%)$ with type 1 PP had a successful vaginal delivery. Significant blood loss of more than $1000 \mathrm{ml}$ was seen in only $10.3 \%$ cases in our study.

Table 4: Maternal outcomes.

\begin{tabular}{|c|c|c|}
\hline & N (\%) & P Value \\
\hline Antepartum hemorrhage (APH) & $17(43.6 \%)$ & 0.34 \\
\hline Post partum hemorrhage (PPH) & $17(43.6 \%)$ & 0.522 \\
\hline Hypovolemic shock & $3(7.7 \%)$ & - \\
\hline $\mathrm{B} / \mathrm{L}$ uterine artery ligation & $5(12.8 \%)$ & $0.00^{*}$ \\
\hline Hysterectomy & $6(15.4 \%)$ & $0.00^{*}$ \\
\hline ICU admission & $6(15.4 \%)$ & $0.00^{*}$ \\
\hline \multicolumn{3}{|c|}{ Duration of Hospital Stay } \\
\hline$<14$ days & $28(71.8 \%)$ & \multirow{2}{*}{$0.010^{*}$} \\
\hline$>/=14$ days & $11(28.2 \%)$ & \\
\hline \multicolumn{3}{|c|}{ Blood Transfusion [N=17] } \\
\hline $1-2$ units & $10(58.8 \%)$ & \multirow{3}{*}{0.52} \\
\hline 3-4 units & $5(29.4 \%)$ & \\
\hline$>/=5$ units & $2(11.8 \%)$ & \\
\hline Maternal mortality & 0 & - \\
\hline
\end{tabular}

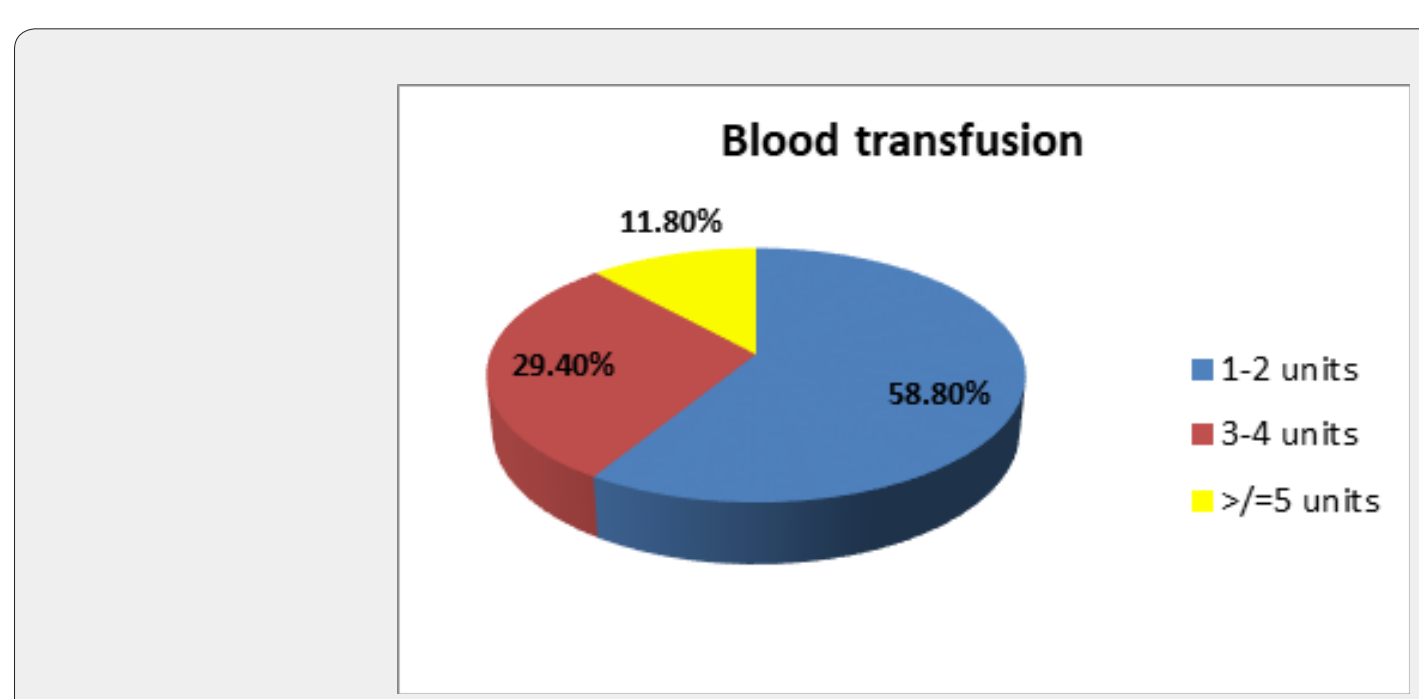

Figure 3: With respect to maternal outcome, $43.6 \%$ cases had antepartum and postpartum (mostly atonic) hemorrhage. 
(Table 4) (Figure 3) With respect to maternal outcome, $43.6 \%$ cases had antepartum and postpartum (mostly atonic) hemorrhage. In terms of surgical interventions, $12.8 \%$ of cases with PP had undergone stepwise devascularisation and 15.4\% cases required caesarean hysterectomy. $15.4 \%$ cases required ICU admission out of which $7.7 \%$ had hypovolemic shock. $28.2 \%$ of patients with PP required hospital stay of more than 14 days. There was no maternal mortality noted in our study. $43.6 \%$ cases required blood transfusion majority of which were cases with placenta accreta. Majority of cases recovered with 1-2 units of blood transfusion.

(Table 5) Perinatal outcomes were mostly favourable with $33.3 \%$ babies requiring NICU admission. These babies had APGAR $<7$ at 5 minutes after birth. Most babies (43.6\%) were beyond $2.5 \mathrm{~kg}$ birth weight. There were no babies born with any congenital anomaly. 1 case of neonatal mortality was observed in our study due to extreme prematurity with birth weight of 640 grams.

Table 5: Perinatal outcomes.

\begin{tabular}{|c|c|c|}
\hline & N (\%) & $P$ Value \\
\hline Admission to NICU & $13(33.3 \%)$ & 0.055 \\
\hline Stillbirth/neonatal death & $1(2.6 \%)$ & - \\
\hline \multicolumn{3}{|c|}{ Birth Weight in Grams } \\
\hline$<1500$ grams & $6(15.4 \%)$ & \multirow{3}{*}{0.058} \\
\hline $1500-2500$ grams & $16(41 \%)$ & \\
\hline$>2500$ grams & $17(43.6 \%)$ & \\
\hline \multicolumn{3}{|c|}{ APGAR Score at 1 minute } \\
\hline$<7$ & $18(46.2 \%)$ & \multirow{2}{*}{0.749} \\
\hline$>/=7$ & $21(53.8 \%)$ & \\
\hline \multicolumn{3}{|c|}{ APGAR Score at 5 minutes } \\
\hline$<7$ & $13(33.3 \%)$ & \multirow{2}{*}{0.55} \\
\hline$>/=7$ & $26(66.7 \%)$ & \\
\hline Congenital malformations & $0(0 \%)$ & - \\
\hline
\end{tabular}

\section{Discussion}

The prevalence of placenta previa in our study was $0.48 \%$ which was higher than those reported by Ramli et al. [7] Rabia Akram et al. [8] The present study indicates that maternal morbidity is significantly increased if PP is complicated by PA. Majority of women belonged to 25- 35 years age group with $71.8 \%$ cases being parous women. Similar findings were noted in a study done by Prasad Usha et al. [9] that showed the highest number of cases with PP was in the age group 25 - 29 with 46 cases (54.76\%) and the incidence was highest among multiparous women $(66$ cases) with 78.57\%.The incidence of placenta accreta in our study was $20.5 \%$. The high incidence of accreta in our study could be attributed to our hospital being a tertiary referral centre. Sarojini et al. [10] reported that $0.64 \%$ of the deliveries were complicated with placenta previa and that $4.7 \%$ had adherent placenta.

Gilliam et al. [11] also reported an increasing incidence of PP as both parity and number of previous Caesarean sections increased and found that the joint effect of parity and prior Caesarean section was greater than that of either variable alone; the likelihood of PP in a woman with parity greater than four and with more than four previous Caesarean sections was almost nine-fold greater (OR 8.76; 95\% CI 1.58-48.53). Likewise, our study also showed significant association of parity and history of previous caesarean section with the incidence of placenta previa. The incidence of previous section among patients with PP in our study was $61.5 \%$. Therefore, it would be reasonable to consider stringent measures to reduce the rate of primary and repeat caesarean sections without increasing maternal-fetal compromise. Many strategies are proposed, among them reducing caesarean sections upon maternal request and encouraging a trial of vaginal delivery after caesarean section. Counselling of such patients should include the remote complications of repeat caesarean section, such as PA. The mean gestational age at delivery in our study was 249 days which is similar to that reported by SK Das et al. [12].

With respect to types of placenta previa based on classification given by Jaunix and Campbell, $41 \%$ of the cases with PP had type IV or central/complete placenta previa and also accounted for majority of cases with placenta accreta (75\%). 17.9\% of cases had type I PP and least common was type IIb (posterior) PP accounting for $7.7 \%$ cases. However the most common types of PP in a study by Bhuyar S et al. [13] were Type I (28.2\%) and Type IIa (28.2\%) followed by Type III (21.8\%), Type IIb (14.1\%), and Type IV (7.8\%).

$61.5 \%$ cases in our study were delivered by emergency caesarean section. LSCS was preferred mode of delivery even in minor PP (type 1 and type 2a) due to associated APH and other obstetric complications like previous LSCS, non-reassuring NST and meconium stained liquor. Ojha $\mathrm{N}[14]$ reported that of the 
total LSCS performed 40 (57\%) cases were emergency operations. 29 (41\%) cases presented with bleeding per vagina. Sekiguchi A et al. [15] conducted a retrospective study on 162 women who were diagnosed to have PP and studied the need for emergency caesarean delivery for torrential vaginal bleeding in incomplete and complete PP. It was observed that 15(19.2\%) patients required blood transfusion out of which 13 patients had major PP. Ojha $\mathrm{N}$ in a retrospective study reported one third (31.4\%) of the patients had blood loss $500 \mathrm{ml}$. There were four cases with blood loss $\geq 1000 \mathrm{ml}$.Among them two had loss of more than two liters. Ten patients required blood transfusion.

Kassem GA et al. [16] showed median intraoperative blood loss in cases of Placenta previa was 1 litre and in placenta accreta was 2,000 (mean 3,000) $\mathrm{ml}$, with a loss of $\geq 2,000 \mathrm{ml}$ occurring in $72 \%$, and $\geq 5,000 \mathrm{ml}$ in $20 \%$. The median packed red blood cell transfusion requirement was 6 (mean 7.7) units, and $28 \%$ received $\geq 10$ units. However, in our study, post-partum hemorrhage was noted in $43.6 \%$ cases and blood loss exceeded 1 later in all cases with placenta accreta accounting for $10.3 \%$ cases. The blood transfusion requirement was seen in $43.6 \%$ cases with majority requiring only 1-2 units of blood transfusion. Ligation to control bleeding was done in $12.8 \%$ cases. Hysterectomy was required in cases of Adherent placenta in 6 cases (15.4\%). Duration of hospital stay of more than 2 weeks in our study was $28.2 \%$ as compared to $10.61 \%$ reported by SK Das et al. [12].

Hebbar SS et al. [17] in a retrospective study reported mean birth weight to be lower than $2.5 \mathrm{~kg}$. However, in our study majority babies had birth weight more than $2.5 \mathrm{~kg}$. In our study neonatal morbidity in terms of NICU admission was seen in $33.3 \%$ of babies and neonatal death seen in $2.6 \%(n=1)$ cases. We noted that there was a progressive decrease in neonatal morbidity in the form of improving Apgar scores and fewer admissions to the neonatal intensive care unit as gestation advanced. Similar findings were reported by Prashanth S et al. [18] in which perinatal morbidity was studied as the percentage of babies requiring resuscitation and NICU admission which was $37.35 \%(n=65)$ and there were $1.72 \%(n=3)$ perinatal deaths.

The strengths of this study are that the patient files were reviewed by the authors themselves, the PP management protocol did not change during the study period, and the authors were working in the hospital during the study, and some cases were managed by them. However, the study has some limitations, i.e., it was retrospective in nature and included a relatively small number of patients and since majority were referred cases the antenatal care received could not be adequately evaluated.

\section{Conclusion}

With the current increase in the rate of caesarean sections the incidence of placenta previa and placenta accrete is gradually increasing. The key risk factors for placenta previaare multigravidas, previous caesarean section, history of previous miscarriage requiring evacuation, inadequate antenatal care. This study highlights that these risk factors may be useful for screening at-risk mothers. Placenta previa was found to indicate a significant risk of severe, adverse maternal and fetal outcomes. It also heralds the need for comprehensive obstetrics care to appropriately treat placenta previa and its complications.

\section{References}

1. Cunningham FG, Leveno KJ, Bloom SL, Haulh JC, Gilstrap LC, et al. (2005) Obstetric haemorrhage. In: Williams Textbook of Obstetrics, In: (22nd edn) McGraw-Hill, New York, USA 20: 809-823.

2. Faiz AS, Ananth CV (2003) Etiology and risk factors for placenta previa: an overview and meta-analysis of observational studies. J Matern Fetal Neonatal Med 13(3): 175-190.

3. Hung TH, Hsieh CC, Hsu JJ, Chiu TH, Lo LM, et al. (2007) Risk factors for placenta previa in an Asian population. Int J Gynecol Obstet 97(1): 26-30.

4. Cresswell JA, Ronsmans C, Calvert C, Filippi V (2013) Prevalence of placenta praevia by world region: a systematic review and metaanalysis. Trop Med Int Healthvol 18(6): 712-724.

5. James DK, Steer PJ, Weiner CP, Gonic B (2010) Bleeding in Late Pregnancy. In: Text book of High Risk Pregnancy Management Options, In: (3rd edn), Saunders, 59:1259-1266.

6. Machado LS (2011) Emergency peripartum hysterectomy: Incidence, indications, risk factors and outcome. N Am J Med Sci 3(8): 358-361.

7. Ramli R, Kamaruddin KA, Him LJ, Aziz AMA, Ramli N, et al. (2019) Morbidly adherent placenta: One-year case series in a tertiary hospital. Med J Malaysia 74(2): 128-132.

8. Akram SAR, Fatima T, Aslam M, Zafar A, Iqbal S, et al. (2020) Fetomaternal outcome with placenta previa and morbidly adherent placenta, a cross sectional study. International Journal of Contemporary Medical Research 7(3): C5-C8.

9. Usha P (2018) A Study of Maternal and Perinatal Outcome in Placenta Previa at A Tertiary Care Centre in Andhra Pradesh. IOSR Journal of Dental and Medical Sciences (IOSR-JDMS) 17(10): 9-12.

10. Sarojini, Malini KV, Radhika (2016) Clinical study of placenta previa and its effect on maternal health and fetal outcome. Int J Reprod Contracept Obstet Gynecol 5(10): 3496-3499.

11. Gilliam M, Rosenberg D, Davis F (2002) The likelihood of placenta previa with greater number of cesarean deliveries and higher parity. Obstet Gynecol 99(6): 976-980.

12. Das SK, Das BP, Baruah Z (2019) Incidence of Placenta Previa in Post Caesarean Pregnancy and Maternal Outcome. Indian Journal of Applied Research 9(11): 33-35.

13. Bhuyar S, Dharmale N (2018) Study of maternal and fetal outcome in various types of placenta previa. Int J Reprod Contracept Obstet Gynecol 7(11): 4652-4656.

14. Ojha N (2012) Obstetric factors and pregnancy outcome in placenta previa. Journal of Institute of Medicine Nepal 34(2): 38-41.

15. Sekiguchi A, Nakai A, Kawabata I, Hayashi M, Takeshita T, et al. (2013) Type and location of placenta previa affect preterm delivery risk related to antepartum hemorrhage. Int J Med Sci 10(12): 1683-1688.

16. Kassem GA, Zahrani AA (2013) Maternal and neonatal Outcome of Placenta Previa and placenta accreta: Three years of experience with two consultant approach. Int J of Woman's health 5: 803-810. 
17. Hebbar SS, Rai L, Zainab R, Guruvare S, Adiga P, et al. (2017) Influence of placental position on obstetric morbidity in placenta previa. International JReproduct, Contracep, Obstet, Gynecol 3(3): 585-591.
18. Prasanth S, Mehta P, Rajeshwari KS (2016) Maternal and fetal outcome of placenta previa in a tertiary care Institute: A prospective two year study. Indian Journal of Obstetrics and Gynecology Research 3(3): 274 278.

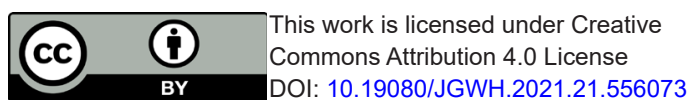

\section{Your next submission with Juniper Publishers will reach you the below assets}

- Quality Editorial service

- Swift Peer Review

- Reprints availability

- E-prints Service

- Manuscript Podcast for convenient understanding

- Global attainment for your research

- Manuscript accessibility in different formats

( Pdf, E-pub, Full Tsext, Audio)

- Unceasing customer service

Track the below URL for one-step submission https://juniperpublishers.com/online-submission.php 